International Center for Public Policy

Working Paper 15-07

November 2015

How large do multi-region models need to

be?

Florenz Plassman

Andrew Feltenstein 

$\underset{\substack{\text { Georgastate } \\ \text { University }}}{\iint_{\text {OF POLICY STUDIES }} \mid} \mid \frac{\text { ANDREW YOUNG SCHOOL }}{\text { S S }}$

International Center for Public Policy

Working Paper 15-07

How large do multi-region models need to be?

Florenz Plassmann

Andrew Feltenstein

November 2015 


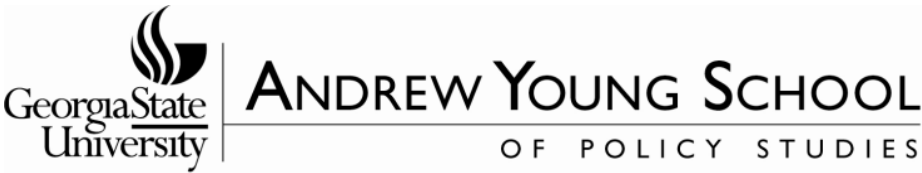

\section{International Center for Public Policy Andrew Young School of Policy Studies}

The Andrew Young School of Policy Studies was established at Georgia State University with the objective of promoting excellence in the design, implementation, and evaluation of public policy. In addition to two academic departments (economics and public administration), the Andrew Young School houses seven leading research centers and policy programs, including the International Center for Public Policy.

The mission of the International Center for Public Policy is to provide academic and professional training, applied research, and technical assistance in support of sound public policy and sustainable economic growth in developing and transitional economies.

The International Center for Public Policy at the Andrew Young School of Policy Studies is recognized worldwide for its efforts in support of economic and public policy reforms through technical assistance and training around the world. This reputation has been built serving a diverse client base, including the World Bank, the U.S. Agency for International Development (USAID), the United Nations Development Programme (UNDP), finance ministries, government organizations, legislative bodies and private sector institutions.

The success of the International Center for Public Policy reflects the breadth and depth of the inhouse technical expertise that the International Center for Public Policy can draw upon. The Andrew Young School's faculty are leading experts in economics and public policy and have authored books, published in major academic and technical journals, and have extensive experience in designing and implementing technical assistance and training programs. Andrew Young School faculty have been active in policy reform in over 40 countries around the world. Our technical assistance strategy is not to merely provide technical prescriptions for policy reform, but to engage in a collaborative effort with the host government and donor agency to identify and analyze the issues at hand, arrive at policy solutions and implement reforms.

The International Center for Public Policy specializes in four broad policy areas:

- Fiscal policy, including tax reforms, public expenditure reviews, tax administration reform

- Fiscal decentralization, including fiscal decentralization reforms, design of intergovernmental transfer systems, urban government finance

- Budgeting and fiscal management, including local government budgeting, performancebased budgeting, capital budgeting, multi-year budgeting

- Economic analysis and revenue forecasting, including micro-simulation, time series forecasting,

For more information about our technical assistance activities and training programs, please visit our website at http://aysps.gsu.edu/isp/index.html or contact us by email at gbotello1@gsu.edu 


\title{
How large do multi-region models need to be?
}

\author{
Florenz Plassmann ${ }^{1}$ \\ Department of Economics, Binghamton University \\ Binghamton, NY 13902-6000 \\ fplass@binghamton.edu \\ Andrew Feltenstein \\ Department of Economics, Georgia State University \\ Atlanta, GA 30303 \\ afeltenstein@gsu.edu
}

\begin{abstract}
:
Given the connectedness of most states with their neighbors, any economic analysis of changes in a state's policy needs to account for the interdependence between states. We examine in how much detail one needs to model the factor and commodity flows between states, and how much, if anything, is lost in the aggregation of neighboring states into larger regions. We develop nine dynamic multi-region general equilibrium models of the United States, with different aggregations of states (a two-region model, a 7-region model, and a full 51-region model) and different assumptions regarding intermediate inputs. We examine the same policy change with these nine models, and find that all nine models suggest very similar economic effects of the policy change in the first year. Our overall conclusion is that the policy implications that one might draw from small and highly aggregate models are fairly robust.
\end{abstract}

Keywords: Multi-region tax model, non-Armington, computational general equilibrium

Journal of Economic Literature Classification Codes: D58, H71, H73

\footnotetext{
${ }^{1}$ Corresponding author. We thank Mark Rider and David Sjoquist for helpful comments and Jeffrey Condon for effective research assistance.
} 


\section{Introduction}

Consider the task of analyzing the expected effects of a change in the economic policy of a state in the US. For example, there is an active debate in the Georgia legislature about whether Georgia should replace its state income tax with either a value added tax or a sales tax. A useful starting point for an analysis of the expected economic consequences of such policy changes is to view the US states as small open economies with fixed exchange rates - states do not have individual monetary policies, capital as well as labor is fairly mobile across state borders, and every state trades intermediate as well as final goods with the other US states and with foreign countries. While any study of a specific state's economic policy needs to account for such interdependence, it is not obvious in how much detail does one need to model these factor and commodity flows if the primary interest is in how changes in a state's economic policy affect this state's economy. Is it sufficient to combine the other states into a single "rest of the US?" Does one need to include at least the state's immediate neighbors? Or does one need to model all 50 states and the District of Columbia explicitly? For example, Feltenstein (1997) constructs a model of the state of Western Australia that is embedded in a single larger model of the rest of Australia. ${ }^{2}$ Mutti et al. $(1989,1995)$ analyze models in which the US states are aggregated into six regions. Plassmann (2005) and Dixon et al. (2012) develop models of all 50 US states plus the District of Columbia. ${ }^{3}$ One purpose of this paper is to examine how much, if anything, is lost in the aggregation of individual states into larger regions.

The issue of aggregation is important for two reasons. First, multi-region models require modelers to represent each state's fiscal policy. Collecting information on marginal tax rates, and determining effective (average) tax rates as well as levels of spending and other fiscal parameters can be quite difficult for a single state, let alone for several states. Conversely, if several states are to be combined into the "rest of the

\footnotetext{
${ }^{2}$ Recent examples of such two-region models of a larger economy include Rose and Liao (2005), Andre et al. (2005), Faulk et al. (2010), Radulescu and Stimmelmayr (2010), and Giesack (2011).

3 Similarly, Adams et al. (2000) develop of six-region model of the Australian states, and Haddad and Perobelli (2005) develop a 27-region model of the Brazilian economy.
} 
United States," then one needs to calibrate a fiscal policy of this artificial region that corresponds to the aggregate fiscal policies of the individual states that this region represents. It is useful to know whether (1) the effort of gathering data for multiple states is worthwhile if one is primarily interested in the economic policy of a single state, and (2) whether calibrating economic policies for an artificial aggregate region introduces distortions.

A second reason why aggregation requires some thought stems from the need to model the technological structure of the industries in each region. Researchers often use applied general equilibrium models to simulate the economic effects of policy changes. Such models permit the description of production processes in considerable detail, for example, as a combination of intermediate inputs and value added. Intermediate inputs are generally modeled with input-output (IO) matrices. The Bureau of Economic Analysis (BEA) offers, free of charge, the IO matrix for the entire Unites States on which the official national income and product accounts are based. IO matrices on the statelevel, however, are not freely available - for example, the Minnesota IMPLAN Group (MIG) sells state-level IMPLAN IO matrices for about $\$ 1,000$ per state. Because the acquisition of such matrices puts a considerable burden on researchers' budgets, it is useful to know how much additional precision these state-specific IO matrices provide. How do simulation results differ if one assumes that the aggregate IO matrix for the United States is an acceptable approximation for state-specific IO matrices, and how much is gained by acquiring state-specific IO matrices? Answering this question is the paper's second purpose.

We address the two questions with nine dynamic multi-region general equilibrium models of the United States; these models describe different aggregations of states (a two-region model, a 7-region model, and a full 51-region model) and different assumptions regarding intermediate inputs (different IO tables for each region, identical IO tables in all regions, and no intermediate inputs). We use Georgia as our reference state because we have access to the state-level MIG IO matrices of Georgia and its five 
immediate neighbors Alabama, Florida, North Carolina, South Carolina, and Tennessee. We simulate the economic effects of abolishing Georgia's personal income tax. We chose this policy not because we want to advocate it as a desirable tax change but rather because abolishing a state's personal income tax without increasing a different tax to keep tax revenue unchanged promises to generate sufficiently large economic effects to make a comparison of different models interesting. In addition, by modeling the effect of abolishing the personal income tax without any corresponding reduction in government spending, our analysis provides an upper bound of the economic consequences of the tax change that the Georgia legislature is currently considering. Thus our exercise provides some information for this ongoing debate.

We draw two surprisingly strong conclusions from our comparison of the nine models. First, all nine models suggest very similar economic effects of the tax change in the first year. Models that differ only by the number of regions imply virtually identical immediate effects of the tax change. The variations across models that make different assumptions regarding the use of intermediate inputs are very minor. Thus if one's main interest is in the immediate effects of a local policy change on the state's own economy, then the simplest and cheapest model - a two-region model of the state of interest and the "rest of the United States" that assumes identical IO matrices in the two regions-is no less accurate than more elaborate models are.

Second, we find that the differences in the descriptions of intermediate inputs across models lead to slightly different assumptions regarding the use of capital and labor across regions and industries; as a consequence, the different models suggest somewhat different growth paths and growth paths that vary somewhat in response to the policy change in one state. It is not obvious which of these models offers the best prediction of economic growth. But because the predicted changes in various economic variables ten years after the implementation of the policy change are still very similar across the nine models, our overall conclusion is that the policy implications that one might draw from small and highly aggregate models are fairly robust. 
The remainder of this paper is organized as follows: in section 2 we suggest that interstate trade in multi-region models ought to be modeled differently from international trade in multi-country models. In section 3 we describe the general set-up of our models, and we describe the model calibration in section 4 . Section 5 is the heart of the paper where we report our simulations results. Section 6 concludes.

\section{Accommodating interstate trade in a multi-region model of the US economy}

Wages in agriculture tend to be lower than wages in mining and manufacturing, and wages in the southern US states are generally lower than wages in the northeastern and western states. These wage differentials reflect partly differences in human capital, partly differences in the general costs of living and the relative attractiveness of different locations, and partly imperfect labor mobility. Any multi-region model of the United States needs to accommodate such wage differentials across different industries as well as across states.

Differences in factor prices - and, more generally, differences in the costs of production across states that arise from different production functions-pose difficulties for multi-region general equilibrium models if these cost differences translate into different output prices. If goods from different states are perfect substitutes for each other, then consumers will acquire these goods only from the state with the lowest production cost and hence the lowest price. To avoid such corner solutions which imply, unrealistically, that each good is produced only in one state, models of international trade generally incorporate the so-called Armington assumption that goods produced in different countries are imperfect substitutes for each other (see Armington, 1969). This assumption yields an intuitively plausible explanation for trade in seemingly identical final goods - for example, if consumers view German cars and Japanese cars as being distinct goods, then it is plausible that Germany and Japan would trade cars with each other. Hence the Armington approach distinguishes final goods by physical 
characteristics as well as by place of origin. The Armington assumption has been used widely in CGE models since its introduction in the ORANI model of Australia (see Dixon et al., 1982).

However, while the Armington assumption is appropriate as a motivation of international trade in final goods, the assumption is less appropriate as an explanation of interregional commodity flows in final goods and intermediate inputs between the states of the US. ${ }^{4}$ Many companies produce identical goods in different plants that are located in different states, but because the units produced in different states are indistinguishable from each other, consumers generally do not care in which state the particular unit that they acquire has been produced. For example, it is difficult to argue that Netflix customers who obtain DVDs by mail care whether their DVD requests were fulfilled by a facility located within their own state or a neighboring state. Similarly, customers of Amazon.com tend to be indifferent about the location of the warehouse that fulfills their orders.

Often goods that are produced by different companies in different states are identical or at least very close substitutes. For example, shipping is generally an intermediate input rather than a final product, and many recipients of mail-orders are indifferent to whether their goods are shipped with UPS (whose headquarters are in Atlanta, GA) or FedEx (whose headquarters are located in Memphis, TN). Frequently there is no substantial difference between, say, pieces of wood harvested and processed in different states that serve as intermediate inputs for, say, furniture. In addition, limited availability of the data necessary to calibrate multi-region models often requires that researchers aggregate individual commodities into broad categories like "agriculture," "manufacturing," or "services." Thus in models that aggregate all agricultural products into the industry "agriculture," differences between oranges harvested in Florida and

\footnotetext{
${ }^{4}$ One might also argue that the Armington approach is inappropriate as a description of international trade in intermediate goods. For example, it seems inappropriate to use the claim that memory chips made in South Korea and Singapore are sufficiently different from each other as an explanation for the observation that Singapore and South Korea trade memory chips with each other.
} 
oranges harvested in California - and even the differences between goods like Virginia ham and Maine lobsters - are greatly diminished. At such levels of aggregation, the degree of substitutability between commodities produced in different states is likely to be fairly high.

We accommodate these observations by assuming that otherwise identical commodities produced in different states are perfect substitutes for each other. Plassmann (2005) offers evidence that policy analyses undertaken with models that assume infinite elasticities of interregional substitution yield very similar results compared to analyses of models undertaken that assume elasticities of interregional substitution as low as 5. Thus even if commodities produced in different states are not perfect substitutes for each other, the assumption of perfect substitutability is likely to be a sufficiently close approximation, especially in models that aggregate individual commodities into fairly broad industry-categories.

Our solution algorithm proceeds as follows: consider a single sector-say manufacturing - that operates in all states. If manufacturing output in any state is a perfect substitute for the manufacturing output of other states, then the equilibrium price of manufacturing output must be identical across states. To establish such a single equilibrium price for manufacturing output, we begin with the manufacturing industry in a reference state. ${ }^{5}$ We follow the standard practice and assume that the manufacturing sector in each state has its own two-part production function; one part uses a neoclassical production function that transforms substitutable factor inputs of capital and labor into value added, while the other part uses an IO matrix to describe intermediate inputs that are used in fixed proportions. We use this two-part production function for the manufacturing industry in the reference state, together with the price of capital and the manufacturing wage in the reference state, to determine the output price of the manufacturing sector. We view this price as the equilibrium price of manufacturing

\footnotetext{
${ }^{5}$ In the models that we describe below, we use the "rest of the United States" as reference region in all models with fewer than 51 regions, and we use California as reference state in the models with all 51 states.
} 
output, thus we must ensure that the prices of manufacturing output in all states equal this equilibrium price. If we suppose that there is a single type of capital that is perfectly mobile across states - thus the price of capital is identical across states - but that labor is, at least in the short run, immobile, then we may solve backwards, in every other state, for the wage rate in manufacturing that implies zero economic profits and the same price of manufacturing output as in the reference state. Thus given a price of capital (that is identical across states) and a set of wages for the industries in the reference state, our model yields an equilibrium solution with industry-specific output prices that are identical across states, a single price of capital, and sector and state specific wages. ${ }^{6} \mathrm{We}$ provide a more detailed description of our solution algorithm in the appendix.

In addition to being - as we argue - the appropriate assumption to describe interstate trade flows within the United States, the assumption of perfect substitutability offers three substantial advantages over models that use the Armington assumption. First, our model naturally accommodates the observation that wages differ across industries and states. While it is possible in principle to assume state-and-industryspecific labor in Armington models, such an assumption increases the dimensionality of these models. $^{7}$ Models with large numbers of unknowns are difficult to solve numerically, and researchers commonly need to limit the number of regions for such technical considerations. Avoiding the Armington assumption makes it straightforward to solve large models with many regions and imperfectly mobile labor. ${ }^{8}$

Second, because our model determines trade among states endogenously, it naturally accommodates interstate trade in intermediate inputs. One way of visualizing

\footnotetext{
${ }^{6}$ We solve the model using the algorithm described in Plassmann (2005) and Feltenstein and Plassmann (2008). The earliest version of such an algorithm was developed in Feltenstein (1997) for a single state embedded in a country (the second region).

${ }^{7}$ For example, an Armington model that incorporates state- and industry-specific wages and that describes 51 states and 12 industries per state needs to be solved for $51 \cdot 12=612$ unknown wages. In contrast, our non-Armington model has only one unknown wage per industry in the reference state (that is, 12), regardless of the number of states, because the equilibrium wages in all other states are determined endogenously from the 12 prices of labor and the price of capital.

${ }^{8}$ Dixon et al. (2012) implement and solve a 51-region Armington model of the United States by assuming that all users of a good in a particular region acquire this good in common proportions from all regions.
} 
our algorithm is to assume the existence of a central clearinghouse for each commodity. Because all states produce identical units of the commodity at identical prices, they send their output to the central clearinghouse that satisfies the demand for intermediate inputs and final output of this commodity from all states. Thus each state's net trade flow is determined endogenously as the difference between the production and consumption of this commodity, and there is no need to specify the parameters of interstate trade exogenously. In contrast, Armington models that describe trade in intermediate inputs need to employ an IO matrix that distinguishes all intermediate inputs by region of origin; such IO matrices are rarely available. ${ }^{9}$

Finally, the assumption that consumers view goods from different regions as imperfect substitutes for each other requires estimates of the elasticities of interstate substitution for each final good. While it may be possible to estimate, with sufficient accuracy, such elasticities of substitution for trade among different countries, much of the trade among the US states never enters the official statistics. For example, while the wages paid to local employees of warehouses operated by Amazon.com enter the official statistics on the production of services in that state, no official statistic tracks the destination by state of each parcel that leaves the warehouse and which thus constitutes an export of services. Similarly, no official statistic tracks the locations of customers who purchase flights from United Airways, whose headquarters are in Chicago, IL, and which ought to be counted as part of Illinois' exports of transportation services. This lack of information makes it difficult to estimate the appropriate state-specific elasticities of interstate substitution for different industries for each state. Our assumption of perfect substitutability circumvents this problem.

\footnotetext{
${ }^{9}$ For additional discussion, see Feltenstein and Plassmann (2008, pp.909-913).
} 


\section{Model description}

\subsection{Factor mobility and production}

The remainder of our model is fairly standard, and hence the conclusions that we draw from the analysis are relevant for other applied general equilibrium models. We aggregate all commodities into 12 industries, and we assume that all output is produced with a combination of intermediate inputs as well as labor and capital as value added. ${ }^{10}$ We follow the common practice of describing the structure of intermediate inputs with an IO matrix, and we therefore assume that intermediate inputs enter the production process in fixed proportions. In section 4 we describe how we adjust the IO matrix in each of our nine models.

We include land as part of "capital" in the value added functions of all sectors to avoid the difficulties of determining industry-specific use of land in each state (for which there is only very limited information) and of specifying production functions that describe the degree of substitutability between capital and land in our different (aggregate) industries. We also adopt the standard assumption that capital is perfectly mobile across industries and states, which implies that the price of capital is identical across industries and states. Although the assumption of perfect capital mobility abstracts from the existence of immobile capital like structures and partially mobile capital like large machines, the lack of information regarding the annual flow of capital among states and industries makes it impossible to calibrate "migration functions" for capital. With regard to labor we assume that, during any given year, labor supply is specific to individual industries in individual states so that wages differ across industries and states. We permit workers to migrate across states and across industries after each year, depending on the utility they could gain by working in different industries and states. We use observed changes in employment across industries and states to calibrate

\footnotetext{
10 The 12 industries are (1) agriculture, (2) mining, (3) utilities, (4) construction, (5) manufacturing, (6) trade, (7), transportation, (8) finance und insurance, (9) real estate, (10) services, (11) federal government, (12) state government.
} 
the labor migration functions; these migration functions introduce frictions that prevent instant wage equalization across industries and regions.

\subsection{Consumption and dynamics}

Each state has 12 representative agents who work in the state's 12 industries. These agents represent the initial workforce in each industry, but fractions of each agent can migrate across industries and states between any two years, taking their labor endowments and assets with them. Each representative agent receives income from supplying his labor and assets, as well as from transfers from the federal government and state and local governments.

We model the decision problem of each representative agent with the standard set of nested CES and Cobb-Douglas utility functions. ${ }^{11}$ Specifically, we assume that each representative agent maximizes a lifetime utility function

$$
U=\left(\sum_{t=0}^{\infty} \alpha(t) C(t)^{\frac{\sigma-1}{\sigma}}\right)^{\frac{\sigma}{\sigma-1}},
$$

where $C(t)$ is consumption at time $t$, the $\alpha(t)$ 's are the CES share parameters that are related to the agent's pure rate of time preference, and $\sigma$ is the elasticity of intertemporal substitution. ${ }^{12}$ First, each agent allocates his lifetime wealth so as to finance consumption in each period, he then decides how to divide $C(t)$ among consumption of goods and leisure in each period $t$, and finally he decides how to divide the total consumption of goods among the output from the 12 industries. Because we assume that consumers consider otherwise identical goods produced in different states as perfect substitutes, we do not need to include the usual final step of Armington models in which consumers

\footnotetext{
${ }^{11}$ See, for example, Ballard et al. (1985).

12 We determine the rates of time preferences numerically as part of the solution algorithm so that a family's long-run saving rate converges to a stable value, given their observed ratio of marginal utility to the price index in period zero. The algorithm is described in detail in Tideman et. al. (2002). The advantage of this approach is that the periods can be solved sequentially while maintaining the assumption of perfect foresight, which makes it possible to solve the model for a larger number of periods.
} 
decide how they divide their consumption of industry output among the units produced in different states.

\subsection{Governments}

All governments make transfers to consumers, invest in government assets (bonds), and demand intermediate goods to produce public goods. They finance these expenditures by levying taxes on the use of capital (corporate income taxes as well as property taxes), personal income taxes on labor and asset income, sales taxes on the consumption of goods, as well as by issuing public debt. Because the model abstracts from risk, consumers view the holding of public debt and investment in new capital as equivalent. Thus the interest on public debt equals the equilibrium return of holding existing capital and investment in new capital. We account for subsidies to different industries by calibrating the effective tax rates on corporate income in these industries accordingly. The federal government makes transfers to and levies taxes on firms and consumers in all states, while each state government makes transfers to and levies taxes on firms and consumers in its own state only.

Because our governments do not use social welfare functions to determine tax rates and spending on transfers and public goods (since we do not know the appropriate weights for such functions that would reflect the actions of the state governments), we need alternative rules to model the behavior of governments over time. We assume that all tax rates remain unchanged over time, and that government spending on public goods is proportional to each state's value of production while government transfers are proportional to each state's total income. We calibrate the values of government spending and government investment for all years in the base case scenario, and we then

use these calibrated values for the years in the counterfactual analyses that assume different tax rates. Other approaches to modeling government expenditures are certainly meaningful, but the assumptions regarding the behavior of governments over time are 
unlikely to have a noticeable influence on our comparison of models with different numbers of regions and different ways of treating intermediate inputs.

\subsection{The rest of the world}

We permit the United States to run a trade deficit with the rest of the world, and assume that the rest of the world supplies any quantity of import demand at the prices that prevail in the United States. Consumers finance their demand for imports by selling fractions of the capital stock and of their holdings of government debt to foreigners. Foreigners use their asset revenue and the proceeds from net exports to finance the governments' budgets deficits and to invest in new capital in the United States.

\section{Nine different models of the US economy}

\subsection{Differences among the nine models}

Table 1 shows the different assumptions regarding the treatment of intermediate inputs and the number of regions that distinguish our models. To simplify the discussion, we divide the nine models into three sets, with three models in each set.

We have access to the aggregate IO matrix for the entire United States as well as to six state-specific IO matrices for Alabama, Florida, Georgia, North Carolina, South Carolina, and Tennessee. Our first set of models (models 1 to 3 ) describes three models that use different IO matrices for each region. ${ }^{13}$ Those in the second set (models 4 to 6 ) use the same IO matrix for all regions. The models in the third set (models 7 to 9) incorporate the structure of value added derived from the aggregate IO matrices but do not incorporate the fixed coefficient flows of intermediate goods - that is, we assume that all output is produced only with labor and capital and that there are no intermediate inputs. Thus the first set of models represents the expensive option of model-building that

\footnotetext{
${ }^{13}$ Because we have access only to the IO matrices of Georgia and its five immediate neighbors, we cannot calibrate a full 51-state model with different IO matrices for each state. Instead, we use the same IO matrix (the aggregate matrix for the entire US) for each of the 45 states other than Georgia and its five immediate neighbors. While it is somewhat misleading to call model 3 a 51 -state model with different IO matrices, we use this label for the sake of notational simplicity.
} 
requires state-specific IO matrices, the second set of models is considerably cheaper because it can be implemented with the single aggregate IO matrix for the United States that is available on the BEA's website, and the third set of models is a stripped down version with fewer data and computational requirements than the other two sets. Comparisons of models across the three rows in Table 1 thus permit us to assess the consequences of employing different assumptions regarding intermediate inputs.

Table 2 shows the shares of value added and its three components - the demand for labor, for capital, and indirect taxes for the 12 industries - in the aggregate IO matrix for the United States as well as in the six state-specific IO matrices for Georgia and its five neighbors. We compiled all entries from the MIG data. For several industries, the total share of value added as well as its composition differs considerably across the seven IO matrices. Thus it seems reasonable to expect that simulations with models that consider region-specific IO matrices (those in set 1) will differ from the simulations with models that assume that all regions share the same IO matrix (those in set 2).

Within each of these three sets of models, we examine three models that describe different numbers of regions. The first model in each set describes two regions: the state of Georgia and a second region that is an aggregate of the remaining 50 states (for simplicity we refer to the District of Columbia as a state). The second model in each set describes seven regions: Georgia, its five immediate neighbors Alabama, Florida, North Carolina, South Carolina, Tennessee, and a seventh region that is an aggregate of the remaining 45 states. The third model describes all 51 states separately. Comparisons of models across the three columns in Table 1 thus permit us to assess the consequences of aggregating states into larger regions.

\subsection{Calibrating the nine models}

We calibrated all models to reflect the economic situation in 2009, which is the most recent year for which state-level data are available. We obtained the seven IO matrices from MIG and all other data from the BEA. Because our main goal is to compare the 
outcomes of the nine models with each other, we calibrated all models to base case scenarios that are as similar as possible. ${ }^{14}$

It is straightforward to calibrate different models to an identical base case scenario as long as these models employ identical assumptions about the use of intermediate inputs and differ only in the number of regions that they describe. However, models in sets 1 and 2 use different sets of IO matrices, and therefore imply different total factor demands for labor and capital in value added in the base case solution. As a consequence, the base case scenarios of the models across the two sets necessarily differ. We calibrated the models in set 1 that use region-specific IO matrices as well as the models in set 3 that assume no intermediate inputs (see below) to represent a total value of labor demand of $\$ 7,810.8$ billion and a total value of capital demand of $\$ 5,094.8$. In contrast, we calibrated the models in set 2 that use the same IO matrix in all regions to represent a total value of labor demand of $\$ 7,663.2$ billion and a total value of capital demand of $\$ 5,242.4 .^{15}$ These different factor usages reflect the differences in the composition of value added that arise from using region-specific IO matrices and identical IO matrices, respectively. In our counterfactual simulations we find that the six

\footnotetext{
${ }^{14}$ Differences in factor endowments are a major source of discrepancy in the counterfactual simulations of different models. To eliminate this source of discrepancy, we did not use the aggregate US IO matrix for the "Rest of the United States" in the 2-region and the 7-region models, because doing so would have led to different total values of labor and capital supply across the three models. Instead, we used the 51-region model to calibrate total factor use, and then adjusted the composition of value added - the capital share and the labor share-in the 12 industries in the region "Rest of the United States" in the 2-region and 7-region models to match the total values of the supply of labor and capital in the 51-region model. Thus the 2region and 7-region models differ somewhat from the respective models that one would calibrate without access to a 51-region model. However, we also examined 2-region and 7-region models for which we used the original US IO matrix for the "Rest of the United States," and the simulation results were almost identical to those presented in Section 5. Thus we conclude that it is appropriate to use the national IO matrix for the aggregate region "Rest of the United States" in models that do not describe all 51 states separately.

15 Thus the total net value of factor demand in all nine models is $\$ 12,905.6$. Adding the total net tax on capital (state and federal corporate income taxes plus state and local property taxes minus federal and state industry subsidies) of $\$ 679.6$ billion yields the total value added of $\$ 13,585.2$ billion. Adding state sales taxes and federal excise taxes of $\$ 533.8$ billion yields a 2009 US GDP of $\$ 14,119$ billion. After we had completed the calibration process, the BEA revised its estimate of 2009 US GDP downwards to $\$ 13,973.7$ billion. Because the revision affected only the total value of output of the federal government but not the value of any other industry and because we are primarily interested in a comparison of the nine models, we decided to continue to use the earlier estimate of GDP of $\$ 14,119$ billion to maintain internal consistency with other, still unrevised, data that we used for the calibration.
} 
models that we calibrated to the values implied by region-specific IO matrices (sets 1 and 3) yield almost identical changes in the counterfactual simulations in the first year. The counterfactual simulations with the three models in set 2 that are calibrated to a set of identical IO matrices are slightly different. These slight differences in the predictions are a direct consequence of the different assumptions about factor endowments in the base case scenarios that result from using different IO matrices.

For the third set of models which assume that all output is produced with value added only, we adjusted the published values of demand to reflect the implicit presence of an IO matrix in the available data. For example, the BEA data show that the federal government spent $\$ 986.6$ billion on consumption in 2009 . In the six models with IO matrices, we treat this amount as demand for output of the federal government (industry 11), the production of which leads to intermediate demand for the output of the other sectors as determined by the respective IO matrices. To be able to match the published output values, we calibrated the three models without IO matrix so that government consumption demand (as well as consumer demand) for industry output is distributed as indicated by the IO matrix, rather than assuming that government demands output only from the government sector. Thus our simulations do not reflect the results that one would obtain if one designed and calibrated a model without any access to IO tables. Instead, our simulations are based on models that match the published values in accordance with the assumptions of the underlying IO matrix, but whose counterfactual solutions are obtained under the assumption that the production of output requires no intermediate inputs. This adjustment permits us to interpret differences among the simulations with the three models in set 3 and the simulations with the other six models as the consequence of not using an IO structure for intermediate inputs, rather than as the consequence of calibrating the models to different base cases. 


\section{Simulation results}

For each of the nine models, we derived a counterfactual solution under the assumption that Georgia abolishes its personal income tax. To amplify the changes in the counterfactual analysis and thus to simply the identification of differences across the nine models, we do not assume any compensating changes so as to maintain a balanced budget. Thus our simulations represent an upper limit of the economic effects that one can expect as a consequence of a corresponding tax change that does not alter Georgia's budget balance.

Table 3 shows the percentage changes in several select variables across models for the first year. We note two results: first, the percentage changes of the three models within each set that assume different numbers of regions are virtually identical. Thus if one's primary interest is in how Georgia's economy changes in response to tax changes in Georgia, then a 2-region model is sufficient and the 7-region and 51-region models do not provide additional insights. Second, the percentage changes of the models in set 2 differ somewhat from those of models 1 and 3, but the differences are small. Thus when it comes to an evaluation of the immediate effects of a tax change, the benefit of using state-specific IO matrices instead of the aggregate IO matrix for all states is fairly minor.

The magnitudes as well as the signs of the changes in Table 3 seem reasonable and intuitive. Abolishing the income tax increases Georgia's gross state product by between $1.53 \%$ (for the models in sets 1 and 3) and 1.56\% (set 2). Eliminating the disincentives to work and save lowers the demand for leisure and thus increases labor supply, income, and saving. The increase in consumption that accompanies the increase in income leads to an increase of about $3.3 \%$ in sales tax revenue, and the increase in the demand for capital that accompanies the increased production raises the revenue from taxing capital (the corporate income tax and the property tax) by about $1.5 \%$. Because these revenue increases of about $\$ 550$ million are not sufficient to cover the loss of income tax revenue of about $\$ 8.2$ billion-recall that we do not model corresponding adjustments that keep Georgia's budget balance unchanged - the overall tax revenue falls 
by $28.5 \%$ and the joint budget deficit of Georgia's state and local governments increases by $50 \%$.

The increase in Georgia's budget deficit is financed by the consumers of all regions, and the share of savings that is available for the production of new capital decreases and nationwide investment in new capital falls by slightly more than $0.3 \%$. The flow of capital into Georgia lowers the supply of capital available to the other states, and the six models in sets 1 and 2 suggest a slight decrease in national GDP. As a consequence, federal tax revenue falls and the federal budget deficit increases by between $0.015 \%$ and $0.025 \%$. In contrast, the three models in set 3 suggest that GDP rises by about $0.0004 \%$, so that the federal tax revenue increases by $0.005 \%$ and the federal budget deficit falls by $0.008 \%$. This result is not implausible-whether or not one should expect national GDP to increase depends on whether the increase in Georgia's output exceeds the decrease in the output of all other states. To the extent that income taxes reduce people's incentives to work and save, it is possible that the net effect of eliminating such a distortion would be positive. However, recall that our models are based on the assumption that capital is perfectly mobile across states - the results might be different if our models accounted for frictions in the mobility of capital.

Table 4 shows the percentage changes in the same variables 10 years after the tax change. All nine models indicate that the increase in Georgia's budget deficit that follows the abolishment of the personal income tax reduces national GDP over time. The differences across models are much larger than those in Table 3, and the differences between the models with different regions are comparable to, and in some cases much larger than, the differences across the models with different assumptions regarding intermediate inputs. Most notably, the three 51-region models suggest that Georgia's gross state product increases by almost $20 \%$ after 10 years, while the six 2-region and 7region models indicate a much smaller increase of between $8.8 \%$ and $11.5 \%{ }^{16}$ These

\footnotetext{
16 The three 7-region models as well as the two 51-region models in sets 1 and 2 indicate that federal budget deficit increases by between $0.04 \%$ and $0.07 \%$, while the other five models suggest that the federal budget deficit decreases by about between $0.03 \%$ and $0.1 \%$, despite lower tax revenues. The reason for
} 
differences across the models are the result of minor differences in savings and investment in the early years that, over time, lead to considerable differences in the capital stock. The three 51-region models also predict much larger inflows of capital into Georgia and associated increases in Georgia's labor supply than the other six models. It is interesting that the differences in capital flows are large across models with different numbers of regions, but much more similar across the three sets of models with different assumptions about intermediate inputs and value added.

It is not obvious which model predicts the increase in Georgia's output after 10 years most accurately. The differences indicate a need for careful calibration of interstate capital flows, although data on such flows are sparse. They also serve as a reminder that the uncertainty of predictions increases the farther ahead the point in time is for which the predictions are made. It is thus comforting that the predictions of the changes in the immediate future are very similar across the nine models.

While a 2-region model is appropriate if the only interest is in the economic changes to the state that implements the tax change, a genuine multi-region model provides information about how a state's tax changes affect other states. Table 5 shows how Georgia's abolishment of the personal income tax affects Georgia's five immediate neighbors in the first year. The differences among the six 7-region and 51-region models are very similar to those in Table 3-the differences between the models in set 1 and 3 on the one hand and those in set 2 on the other are slightly larger than the differences between the models with 7-regions and 51-regions, but the differences are very small. ${ }^{17}$

these small discrepancies lies in our treatment of government transfers over time, which we assume vary with changes in state government tax revenues and consumer incomes. It would be possible to calibrate the transfer functions so that the changes in transfers are more similar across the nine models. Alas, it is difficult to assess which of the nine models ought to be the target in such calibrations.

17 The differences for Alabama between the 7-region model and the 51-region model with different IO matrices are an exception. We do not have an explanation for why these differences arise only for Alabama and only for these two models, although we note that the large percentage differences obscure relatively minor differences in the actual values. For example, in the 7-region model the change in Alabama's gross state product is $\ln (\$ 169.038$ bn $/ \$ 169.134$ bn $)=-0.057 \%$, while the same change in the 51-region model is $\ln (\$ 169.099$ bn $/ \$ 169.134 \mathrm{bn})=-0.021 \%$. 
The effects of the tax change are fairly similar across Georgia's neighbors. Gross state products fall by between $0.051 \%$ and $0.071 \%$, although the 7-region and the 51region models in set 3 that assume that production takes place without intermediate inputs suggest a much smaller decrease of $0.024 \%$ for Florida. In general, the detrimental effects on Florida seem more moderate than those on the other states. A likely explanation is that Florida is the only one of Georgia's neighboring states without a state income tax, thus Florida loses less capital. Table 5 supports the conclusion that we drew from Table 3-that Georgia's economic improvement occurs to some extent at the cost of other states.

One might object to this conclusion on the grounds that it violates Ricardian equivalence-in our model, Georgia's creditors ignore the possibility that Georgia will not be able to repay its increasing budget deficit. Our result is a direct consequence of our assumptions that (a) consumers abstract from risk, and (b) Georgia's state government does not adjust its expenditure compared to the base case scenario to accommodate the loss in tax revenue. Most importantly, we do not impose any balanced budget rules, either within periods or as end of period closure rules. In a short or medium term model such as ours, this absence of budget constraints may be appropriate; it would be more difficult to defend in a longer term model.

An analysis whose primary focus is on the economic effects of abolishing the personal income tax ought to incorporate either government spending adjustments or a reluctance of lenders to supply funds to governments with non-sustainable spending patterns. However, since it is not obvious which types of expenditures Georgia's state government would adjust to accommodate the (entirely hypothetical) abolishment of the state income tax, and because our primary focus is on the differences between the nine different models, rather than on the economic consequences of abolishing the income tax, we decided not to pursue this issue any further. 


\section{Conclusion}

We construct a series of nine dynamic general equilibrium models to analyze the economic effect of tax changes in a single state surrounded by competitor states. A key feature of our models is the avoidance of the Armington assumption, because we assume that all intermediate and final goods are perfect substitutes across states. For models of multiple regions within a country, we argue that this approach is superior to the typical Armington trade model that requires elasticities of substitution to be estimated for all traded goods, since such elasticities of interstate substitution can be estimated only with high standard errors of estimate. We examine 3 different model structures, based upon different assumptions regarding the use of intermediate inputs, and for each model structure, we examine three models with different numbers of regions. We conclude that if one's main interest is in the implications of a tax change upon the state's own economy, in this case Georgia, then (1) the simulation results that one obtains with a 2region model are very similar to the results of more elaborate models with more regions, and (2) the data requirements are relatively minor since the use of state-specific IO matrices does not lead to notably different results. Our analysis therefore suggests that for most purposes, small models are sufficient and model builders might not need to purchase multiple expensive data sets. We emphasize that this result is not necessarily universal-for example, it is conceivable that an analysis of a very large state such as California that is surrounded by much smaller states would yield different results than an analysis of a smaller state like Georgia that is surrounded by similarly-sized states. However, because limited funds prevent us from acquiring state-specific IO-tables of California and its neighbors at this time, we leave this additional robustness check for future research. 


\section{Appendix: The Non-Armington Computational Method ${ }^{18}$}

The following algorithm assumes perfect interregional substitutability, and yields the same equilibrium solution as an Armington model with infinite interregional substitutability:

(1) Assume that capital $(K)$ is perfectly mobile (the equilibrium price of capital, $p_{K}$, is the same in all regions) and labor $(L)$ is region- and industry specific ( $p_{L r i}$ is the wage in region $r$ and industry $i, i=1, \ldots, N)$. The model has $N+1$ unknown factor prices. The first $N$ unknown factor prices are the prices of labor in the $N$ industries in region 1. The last unknown price is the price of capital that is valid in each of the $R$ regions.

(2) Let the solution algorithm (for example, a Gauss-Seidel or Newton-Raphson method) choose values for the $N+1$ unknown prices, $p_{L 11}, \ldots, p_{L 1 N}$, and $p_{K}$.

(3) Determine the profit maximizing demand for capital and labor in industry $i$ in region $1, K_{1 i}$, and $L_{1 i}$, by minimizing the cost of producing one unit of output, $C_{1 i}=$ $p_{K} K_{1 i}+p_{L 1 i} L_{1 i}$, subject to the industry's production function. Given factor prices and the per-unit factor demand, the zero-profit condition yields industry $i$ 's unitoutput price, $p_{1 i}=C_{1 i}$. Because of the assumption of perfect substitutability across regions, equilibrium output prices are identical in all regions, so that $p_{1 i}=p_{i} \forall i$.

(4) Use a nonlinear numerical minimization routine that repeats step (3) for industry 1 in region 2 with different values of the wage $p_{L 21}$ to determine the output price $p_{21}$ until it has found the wage $p_{L 21}{ }^{*}$ for which $\left(p_{21}-p_{1}\right)^{2}=0$.

(5) Repeat step (4) for all industries $i=1, \ldots, N$ in all regions $r=2, \ldots, R$.

(6) Solve the utility maximization problems of all consumers in all regions (because labor is region- and industry specific, there are $N * R$ different consumers whose wage incomes may differ) to determine total demand (consumption and investment demand) for output from all industries as well as labor supply to all industries in all regions.

(7) Determine how much output every industry in every region needs to produce to employ all labor supplied.

\footnotetext{
18 The appendix is taken from Plassmann (2005, pp. $785-787)$.
} 
(8) Given industry i's full employment output, divide total demand for industry i's output between the regions so that all regions have equal shares of either excess demand for or excess supply of industry $i$ labor.

(9) Repeat step (8) for all industries.

(10) Repeat steps (2) to (9) until the solution algorithm has found the $N+1$ factor prices that clear all factor markets simultaneously.

Steps (4), (7) and (8) are the important parts of the algorithm. Step (4) determines the wages in all $R-1$ regions and $N$ industries that yield the output prices determined in region 1. There is no algebraic solution for common production functions (for example, Cobb Douglas or CES) and the wages need to be determined numerically. Sequential minimization of $N *(R-1)$ equations with a single unknown variable requires far less time than the simultaneous solution of $N^{*}(R-1)$ equations with $N^{*}(R-1)$ unknowns. The fact that the algorithm requires $N *(R-1)$ numerical minimizations for each repetition of steps (2) to (9) does not increase computation time by any noticeable amount.

Although consumer demand equals supply from all regions in equilibrium, it is necessary to find an allocation rule that determines out-of-equilibrium demand for each region's output that permits the solution algorithm to converge to equilibrium. For example, allocating out-of-equilibrium excess demand or supply only to a subset of regions while assuming that industry $i$ 's labor market clears in the remaining regions prevents the algorithm from converging. Steps (7) and (8) allocate total demand for industry output among the $R$ regions, and ensure that all $R$ labor markets of industry $i$ experience an equal percentage of out-of-equilibrium excess demand or supply of labor. Once the wage that clears industry $i$ 's labor market in region 1 has been determined, all $R$ labor markets of industry $i$ clear simultaneously.

The heart of the algorithm is that perfect substitutability ensures identical equilibrium output prices in all regions. The algorithm is not applicable to cases in which consumers do not view goods from different regions as perfect substitutes for each other. For example, it is straightforward to show that in models that explicitly introduce 
transportation costs, goods from different regions cannot be perfect substitutes. ${ }^{19}$ However, Glaeser and Kohlhase (2004) provide empirical evidence that in the United States the costs of transporting manufactured goods decreased by over 90 percent during the twentieth century while the costs of transporting people have increased. This suggests that the assumptions of zero transportation costs and perfect substitutability may not be farfetched for regional models, and that the assumption that labor is fairly immobile in the short run is appropriate as well.

Three minor adjustments are necessary to incorporate trade in intermediate goods: Step (3) first determines the cost of producing value-added in all industries in region 1, and then uses equation (3) to determine the vector of output prices from region 1's IO table. $^{20}$ Step (7) determines full-employment output (of value added) in each industry and each region, as well as each region's/industry's share of full employment output. If all regions share the same IO-table, then Step (8) first uses the IO table to transform total consumer demand for final goods into total demand for value added. As before, total demand for value added is then allocated among all industries so that each industry faces the same excess demand/supply of labor in all regions. If regions have different IO tables, then the allocation of demand proceeds sequentially. For each industry, Step (8) first allocates total consumer demand for final goods according to each region's share of full employment output. Each region's IO table yields that region's demand for intermediate goods. Total demand for intermediate goods is then allocated according to each region's share of full employment output, and the new demand for intermediate goods necessary to produce the first set of intermediate goods is determined from each region's IO table. The procedure continues until the demand for additional intermediate goods has become small enough to be ignored.

\footnotetext{
${ }^{19}$ Assume that, in region 1 , a good costs $\$ x$ if it is produced in region 1 and $\$ y+t$ if it is produced in region 2 , where $t$ is the cost of transporting the good from one region to the other. In region 2 , the same good costs $\$ y$ if it is produced in region 2 and $\$ x+t$ if it is produced in region 1. Perfect substitutability requires that $x=y+t$ and $y=x+t$ in equilibrium, which is possible only if $t=0$. With positive transportation costs, the assumption of free market entry implies that regional firms operate within the framework of monopolistic competition, in which firms set output prices and quantities to break even in equilibrium. Because there is no a priori reason for equilibrium output prices to be identical across regions, it is not possible to deduce regional wages from output prices.

${ }^{20}$ If regions have different IO tables, then the model requires the assumption that regions $2 \ldots R$ are small relative to region 1 to make it appropriate that output prices are determined in region 1.
} 
Table 1: The number of regions and the assumptions about intermediate inputs across the nine models

\begin{tabular}{l|ccc}
\hline $\begin{array}{l}\text { Number of regions: } \\
\begin{array}{l}\text { Treatment of inter- } \\
\text { mediate inputs } \downarrow\end{array}\end{array}$ & $\begin{array}{c}\text { 2 regions: } \\
\text { Rest of the USA (the } \\
\text { remaining 50 states) }\end{array}$ & $\begin{array}{c}\text { Alabama, Florida, Georgia, North } \\
\text { Carolina, South Carolina, Tennessee, } \\
\text { Rest of the USA (the remaining 45 } \\
\text { states) }\end{array}$ & All 51 US states \\
\hline $\begin{array}{l}\text { Set 1: Region-specific } \\
\text { IO matrices }\end{array}$ & Model 1 & Model 2 & Model 3 \\
$\begin{array}{l}\text { Set 2: All regions use } \\
\text { the same IO matrix }\end{array}$ & Model 4 & Model 5 & Model 6 \\
$\begin{array}{l}\text { Set 3: No } \\
\begin{array}{l}\text { intermediate inputs; } \\
\text { all output is produced } \\
\text { with value added only }\end{array}\end{array}$ & Model 7 & Model 8 & Model 9
\end{tabular}


Table 2. Value added and its composition in 12 industries for the United States and for six southern states

\begin{tabular}{|c|c|c|c|c|c|c|c|c|c|c|c|c|}
\hline & $\frac{\stackrel{0}{\Xi}}{\stackrel{\Xi}{\Xi}}$ & 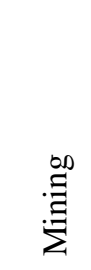 & 总 & 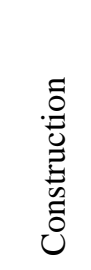 & 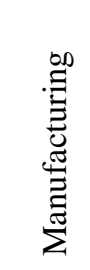 & 苞 & 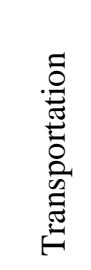 & 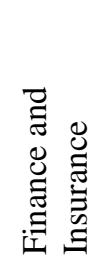 & 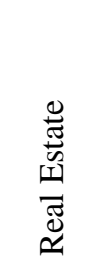 & 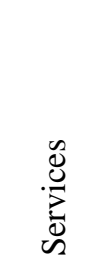 & 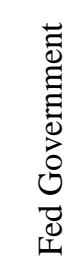 & 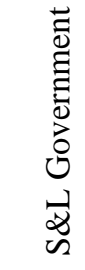 \\
\hline \multicolumn{13}{|l|}{ United States: } \\
\hline Capital & 0.26 & 0.41 & 0.46 & 0.17 & 0.15 & 0.15 & 0.20 & 0.22 & 0.71 & 0.19 & 0.21 & 0.10 \\
\hline + Labor & 0.11 & 0.19 & 0.19 & 0.31 & 0.18 & 0.42 & 0.37 & 0.29 & 0.04 & 0.41 & 0.74 & 0.80 \\
\hline+ Indirect taxes & 0.02 & 0.08 & 0.16 & 0.01 & 0.01 & 0.16 & 0.04 & 0.02 & 0.10 & 0.03 & 0.00 & -0.02 \\
\hline $\begin{array}{l}=\text { Value added } \\
\text { Alabama: }\end{array}$ & 0.38 & 0.68 & 0.81 & 0.49 & 0.35 & 0.73 & 0.61 & 0.53 & 0.85 & 0.64 & 0.95 & 0.88 \\
\hline Capital & 0.30 & 0.46 & 0.49 & 0.19 & 0.20 & 0.16 & 0.24 & 0.25 & 0.74 & 0.19 & 0.19 & 0.11 \\
\hline + Labor & 0.20 & 0.23 & 0.23 & 0.40 & 0.30 & 0.46 & 0.43 & 0.29 & 0.03 & 0.50 & 0.74 & 0.81 \\
\hline+ Indirect taxes & 0.02 & 0.12 & 0.18 & 0.01 & 0.02 & 0.17 & 0.03 & 0.02 & 0.10 & 0.04 & 0.00 & -0.02 \\
\hline $\begin{array}{l}=\text { Value added } \\
\text { Florida: }\end{array}$ & 0.52 & $\mathbf{0 . 8 1}$ & 0.90 & 0.61 & 0.51 & 0.80 & 0.70 & 0.55 & 0.88 & 0.73 & 0.94 & 0.90 \\
\hline Capital & 0.35 & 0.34 & 0.51 & 0.20 & 0.19 & 0.14 & 0.22 & 0.20 & 0.72 & 0.20 & 0.22 & 0.13 \\
\hline + Labor & 0.24 & 0.10 & 0.21 & 0.36 & 0.27 & 0.45 & 0.40 & 0.29 & 0.04 & 0.44 & 0.74 & 0.79 \\
\hline+ Indirect taxes & 0.03 & 0.04 & 0.18 & 0.01 & 0.03 & 0.17 & 0.05 & 0.02 & 0.10 & 0.04 & 0.00 & -0.02 \\
\hline $\begin{array}{l}=\text { Value added } \\
\text { Georgia: }\end{array}$ & 0.61 & 0.48 & 0.90 & 0.56 & 0.49 & 0.75 & 0.67 & 0.51 & 0.87 & 0.68 & 0.96 & 0.90 \\
\hline$\overline{\text { Capital }}$ & 0.32 & 0.37 & 0.55 & 0.22 & 0.28 & 0.16 & 0.21 & 0.26 & 0.73 & 0.23 & 0.25 & 0.11 \\
\hline + Labor & 0.15 & 0.24 & 0.20 & 0.35 & 0.25 & 0.44 & 0.44 & 0.29 & 0.04 & 0.42 & 0.73 & 0.82 \\
\hline+ Indirect taxes & 0.03 & 0.04 & 0.19 & 0.01 & 0.01 & 0.17 & 0.07 & 0.02 & 0.10 & 0.03 & 0.00 & -0.01 \\
\hline $\begin{array}{l}=\text { Value added } \\
\text { North Carolina: }\end{array}$ & 0.50 & 0.65 & 0.93 & 0.58 & 0.54 & 0.77 & 0.71 & 0.57 & 0.87 & 0.69 & 0.98 & 0.92 \\
\hline Capital & 0.36 & 0.46 & 0.51 & 0.22 & 0.26 & 0.16 & 0.22 & 0.24 & 0.73 & 0.18 & 0.31 & 0.13 \\
\hline + Labor & 0.14 & 0.15 & 0.23 & 0.36 & 0.26 & 0.45 & 0.45 & 0.32 & 0.03 & 0.49 & 0.67 & 0.81 \\
\hline+ Indirect taxes & 0.03 & 0.04 & 0.19 & 0.01 & 0.04 & 0.17 & 0.04 & 0.02 & 0.10 & 0.03 & 0.00 & -0.01 \\
\hline $\begin{array}{l}=\text { Value added } \\
\text { South Carolina: }\end{array}$ & 0.53 & 0.65 & 0.93 & 0.60 & 0.56 & 0.78 & 0.71 & 0.58 & 0.87 & 0.71 & 0.98 & 0.93 \\
\hline Capital & 0.33 & 0.39 & 0.52 & 0.21 & 0.22 & 0.15 & 0.21 & 0.24 & 0.74 & 0.20 & 0.29 & 0.11 \\
\hline + Labor & 0.25 & 0.20 & 0.24 & 0.38 & 0.33 & 0.47 & 0.47 & 0.29 & 0.03 & 0.48 & 0.69 & 0.83 \\
\hline+ Indirect taxes & 0.03 & 0.03 & 0.19 & 0.01 & 0.02 & 0.17 & 0.03 & 0.02 & 0.10 & 0.04 & 0.00 & -0.02 \\
\hline $\begin{array}{l}=\text { Value added } \\
\text { Tennessee: }\end{array}$ & 0.61 & 0.62 & 0.95 & 0.60 & 0.57 & 0.79 & 0.70 & 0.56 & 0.87 & 0.72 & 0.98 & 0.92 \\
\hline Capital & 0.35 & 0.45 & 0.51 & 0.22 & 0.24 & 0.17 & 0.26 & 0.26 & 0.74 & 0.24 & 0.16 & 0.12 \\
\hline + Labor & 0.16 & 0.19 & 0.21 & 0.35 & 0.29 & 0.44 & 0.45 & 0.28 & 0.03 & 0.43 & 0.63 & 0.79 \\
\hline+ Indirect taxes & 0.03 & 0.05 & 0.17 & 0.01 & 0.03 & 0.17 & 0.03 & 0.02 & 0.10 & 0.03 & 0.00 & -0.02 \\
\hline$=$ Value added & 0.54 & 0.69 & 0.90 & 0.57 & 0.55 & 0.78 & 0.73 & 0.57 & 0.87 & 0.71 & 0.79 & 0.90 \\
\hline
\end{tabular}

\section{Notes:}

1. The entries are the gross returns to capital and labor and the indirect taxes paid per $\$ 1$ of industry output. Payments for intermediate inputs (not shown) make up the remainder.

2. We compiled all coefficients in this table from MIG's IMPLAN data. 
Table 3. Simulations results for year 0: percentage changes in select variables

\begin{tabular}{|c|c|c|c|c|c|c|c|c|c|}
\hline & \multicolumn{3}{|c|}{$\begin{array}{c}\text { Different IO matrices } \\
(\text { Set } 1)\end{array}$} & \multicolumn{3}{|c|}{$\begin{array}{c}\text { Identical IO matrices } \\
\text { (Set 2) }\end{array}$} & \multicolumn{3}{|c|}{$\begin{array}{c}\text { No IO matrices } \\
\text { (Set 3) }\end{array}$} \\
\hline & $\begin{array}{c}2 \text { regions } \\
\text { (1) }\end{array}$ & $\begin{array}{c}7 \text { regions } \\
(2) \\
\end{array}$ & $\begin{array}{c}51 \text { regions } \\
(3) \\
\end{array}$ & $\begin{array}{c}2 \text { regions } \\
(4)\end{array}$ & $\begin{array}{l}7 \text { regions } \\
(5) \\
\end{array}$ & $\begin{array}{c}51 \text { regions } \\
(6)\end{array}$ & $\begin{array}{c}2 \text { regions } \\
(7)\end{array}$ & $\begin{array}{c}7 \text { regions } \\
(8) \\
\end{array}$ & $\begin{array}{c}51 \text { regions } \\
(9)\end{array}$ \\
\hline & \multicolumn{9}{|c|}{ US economy: } \\
\hline GDP & $-0.008 \%$ & $-0.008 \%$ & $-0.009 \%$ & $-0.012 \%$ & $-0.012 \%$ & $-0.012 \%$ & $0.000 \%$ & $0.000 \%$ & $0.000 \%$ \\
\hline Saving & $0.024 \%$ & $0.024 \%$ & $0.024 \%$ & $0.030 \%$ & $0.030 \%$ & $0.029 \%$ & $0.031 \%$ & $0.031 \%$ & $0.032 \%$ \\
\hline Investment & $-0.347 \%$ & $-0.348 \%$ & $-0.350 \%$ & $-0.350 \%$ & $-0.350 \%$ & $-0.350 \%$ & $-0.320 \%$ & $-0.321 \%$ & $-0.320 \%$ \\
\hline \multicolumn{10}{|l|}{ Federal government } \\
\hline Revenue & $-0.017 \%$ & $-0.017 \%$ & $-0.016 \%$ & $-0.017 \%$ & $-0.017 \%$ & $-0.016 \%$ & $0.006 \%$ & $0.005 \%$ & $0.005 \%$ \\
\hline Deficit & $0.013 \%$ & $0.014 \%$ & $0.015 \%$ & $0.026 \%$ & $0.026 \%$ & $0.025 \%$ & $-0.009 \%$ & $-0.008 \%$ & $-0.008 \%$ \\
\hline \multicolumn{10}{|l|}{ Georgia: } \\
\hline$\overline{\text { Gross state product }}$ & $1.533 \%$ & $1.532 \%$ & $1.531 \%$ & $1.564 \%$ & $1.563 \%$ & $1.563 \%$ & $1.526 \%$ & $1.526 \%$ & $1.526 \%$ \\
\hline Personal income & $1.795 \%$ & $1.795 \%$ & $1.795 \%$ & $1.704 \%$ & $1.704 \%$ & $1.704 \%$ & $1.802 \%$ & $1.802 \%$ & $1.802 \%$ \\
\hline Saving & $2.411 \%$ & $2.411 \%$ & $2.411 \%$ & $2.318 \%$ & $2.298 \%$ & $2.298 \%$ & $2.418 \%$ & $2.418 \%$ & $2.418 \%$ \\
\hline Consumption of & & & & & & & & & \\
\hline goods & $3.306 \%$ & $3.306 \%$ & $3.306 \%$ & $3.280 \%$ & $3.285 \%$ & $3.285 \%$ & $3.312 \%$ & $3.312 \%$ & $3.312 \%$ \\
\hline leisure & $-4.757 \%$ & $-4.758 \%$ & $-4.758 \%$ & $-4.887 \%$ & $-4.882 \%$ & $-4.882 \%$ & $-4.748 \%$ & $-4.749 \%$ & $-4.748 \%$ \\
\hline \multicolumn{10}{|l|}{ Government } \\
\hline Tax revenue & $-28.409 \%$ & $-28.409 \%$ & $-28.409 \%$ & $-28.403 \%$ & $-28.401 \%$ & $-28.401 \%$ & $-28.565 \%$ & $-28.565 \%$ & $-28.565 \%$ \\
\hline Tax on capital & $1.490 \%$ & $1.490 \%$ & $1.490 \%$ & $1.527 \%$ & $1.526 \%$ & $1.526 \%$ & $1.499 \%$ & $1.499 \%$ & $1.499 \%$ \\
\hline Sales tax rev. & $3.306 \%$ & $3.306 \%$ & $3.306 \%$ & $3.280 \%$ & $3.285 \%$ & $3.285 \%$ & $2.979 \%$ & $2.979 \%$ & $2.979 \%$ \\
\hline Deficit & $50.003 \%$ & $50.002 \%$ & $50.003 \%$ & $49.995 \%$ & $49.993 \%$ & $49.993 \%$ & $50.189 \%$ & $50.189 \%$ & $50.189 \%$ \\
\hline
\end{tabular}


Table 4. Simulations results for year 10: percentage changes in select variables

\begin{tabular}{|c|c|c|c|c|c|c|c|c|c|}
\hline & \multicolumn{3}{|c|}{$\begin{array}{c}\text { Different IO matrices } \\
(\text { Set } 1)\end{array}$} & \multicolumn{3}{|c|}{$\begin{array}{l}\text { Identical IO matrices } \\
\text { (Set 2) }\end{array}$} & \multicolumn{3}{|c|}{$\begin{array}{c}\text { No IO matrices } \\
\text { (Set 3) }\end{array}$} \\
\hline & $\begin{array}{c}2 \text { regions } \\
\text { (1) }\end{array}$ & $\begin{array}{c}7 \text { regions } \\
(2) \\
\end{array}$ & $\begin{array}{c}51 \text { regions } \\
(3)\end{array}$ & $\begin{array}{c}2 \text { regions } \\
(4)\end{array}$ & $\begin{array}{c}7 \text { regions } \\
(5) \\
\end{array}$ & $\begin{array}{l}51 \text { regions } \\
(6) \\
\end{array}$ & $\begin{array}{c}2 \text { regions } \\
(7)\end{array}$ & $\begin{array}{c}7 \text { regions } \\
(8) \\
\end{array}$ & $\begin{array}{c}51 \text { regions } \\
(9)\end{array}$ \\
\hline \multicolumn{10}{|l|}{ US economy: } \\
\hline GDP & $-0.854 \%$ & $-1.243 \%$ & $-1.094 \%$ & $-1.274 \%$ & $-1.466 \%$ & $-1.327 \%$ & $-0.279 \%$ & $-0.950 \%$ & $-0.758 \%$ \\
\hline Saving & $-3.468 \%$ & $-4.511 \%$ & $-4.361 \%$ & $-5.109 \%$ & $-5.164 \%$ & $-5.222 \%$ & $-1.436 \%$ & $-3.734 \%$ & $-3.322 \%$ \\
\hline Investment & $-5.214 \%$ & $-6.739 \%$ & $-6.561 \%$ & $-7.450 \%$ & $-7.685 \%$ & $-7.747 \%$ & $-2.355 \%$ & $-5.537 \%$ & $-4.984 \%$ \\
\hline \multicolumn{10}{|l|}{ Federal government } \\
\hline Revenue & $-1.326 \%$ & $-1.538 \%$ & $-1.421 \%$ & $-1.326 \%$ & $-1.538 \%$ & $-1.421 \%$ & $-0.235 \%$ & $-0.866 \%$ & $-0.699 \%$ \\
\hline Deficit & $-0.032 \%$ & $0.058 \%$ & $0.051 \%$ & $-0.101 \%$ & $0.074 \%$ & $0.043 \%$ & $-0.035 \%$ & $-0.049 \%$ & $-0.036 \%$ \\
\hline \multicolumn{10}{|l|}{ Georgia: } \\
\hline$\overline{\text { Gross state product }}$ & $10.637 \%$ & $11.466 \%$ & $19.687 \%$ & $10.427 \%$ & $10.906 \%$ & $19.966 \%$ & $9.649 \%$ & $8.765 \%$ & $19.371 \%$ \\
\hline Personal income & $11.009 \%$ & $11.703 \%$ & $18.879 \%$ & $10.426 \%$ & $10.234 \%$ & $18.544 \%$ & $10.078 \%$ & $10.840 \%$ & $18.802 \%$ \\
\hline Saving & $27.171 \%$ & $32.240 \%$ & $62.433 \%$ & $23.724 \%$ & $23.442 \%$ & $56.919 \%$ & $20.408 \%$ & $26.351 \%$ & $61.443 \%$ \\
\hline Consumption of & & & & & & & & & \\
\hline goods & $9.735 \%$ & $9.487 \%$ & $9.620 \%$ & $9.442 \%$ & $9.202 \%$ & $9.396 \%$ & $9.910 \%$ & $9.656 \%$ & $9.772 \%$ \\
\hline leisure & $1.510 \%$ & $1.222 \%$ & $1.405 \%$ & $1.114 \%$ & $0.838 \%$ & $1.063 \%$ & $1.735 \%$ & $1.402 \%$ & $1.587 \%$ \\
\hline \multicolumn{10}{|l|}{ Government } \\
\hline Tax revenue & $-22.067 \%$ & $-17.053 \%$ & $-16.341 \%$ & $-21.974 \%$ & $-17.738 \%$ & $-16.824 \%$ & $-22.714 \%$ & $-14.332 \%$ & $-17.414 \%$ \\
\hline Tax on capital & $5.431 \%$ & $13.356 \%$ & $17.472 \%$ & $6.909 \%$ & $13.744 \%$ & $18.153 \%$ & $4.906 \%$ & $8.962 \%$ & $16.130 \%$ \\
\hline Sales tax rev. & $9.735 \%$ & $9.486 \%$ & $9.620 \%$ & $9.442 \%$ & $9.202 \%$ & $9.396 \%$ & $8.929 \%$ & $8.580 \%$ & $8.768 \%$ \\
\hline Deficit & $80.979 \%$ & $76.424 \%$ & $77.168 \%$ & $91.844 \%$ & $92.378 \%$ & $94.235 \%$ & $78.528 \%$ & $66.158 \%$ & $79.067 \%$ \\
\hline
\end{tabular}


Table 5. Simulations results for year 0: percentage changes in Georgia and its immediate neighbors

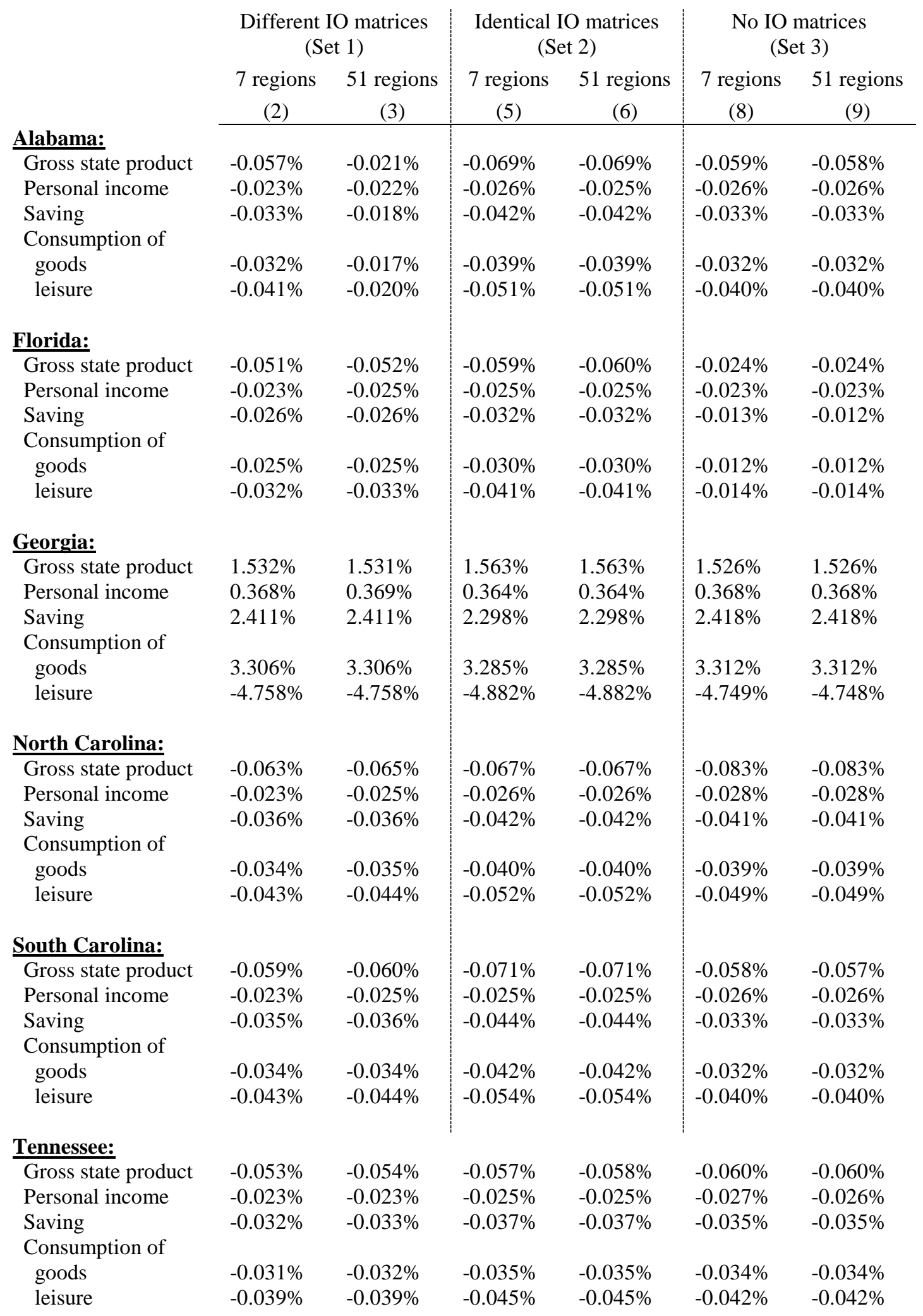




\section{References}

Adams, P. D., M. Horridge, and B. Parmenter. 2000. MMRF-GREEN: A Dynamic, Multi-Sectoral, Multi-Regional Model of Australia. Monash University, Centre of Policy Studies/IMPACT Centre Working Paper no. op-94.

André, F., M. Flores, and E. Velázquez. 2005. "Performing an environmental tax reform in a regional economy. A computable general equilibrium approach." The Annals of Regional Science 39:2, 375-392.

Armington, P. 1969. "A Theory of Demand for Products Distinguished by Place of Production." IMF Staff Papers 16, 159-178.

Ballard, C., J.B. Shoven, and J. Whalley (1985), "General Equilibrium Computations of the Marginal Welfare Costs of Taxation in the United States." American Economic Review 75: 128-138.

Dixon, P. B., B. R. Parmenter, J. Sutton and D. P. Vincent (1982). ORANI, $a$ Multisectoral Model of the Australian Economy. North-Holland, Amsterdam.

Dixon, P. B., M. Rimmer, G. Wittmer. 2012. "USAGE-R51, a state-level multi-regional CGE model of the US economy." GTAP Conference Paper, Purdue University.

Faulk, D., N. Thaiprasert, and M. Hicks. 2010. "The Economic Effects of Replacing the Property Tax with a Sales or Income Tax: A Computable General Equilibrium Approach." Working Paper No. 201008, Department of Economics, Ball State University.

Feltenstein, A. 1997. “An Analysis of the Implications for the Gold Mining Industry of Alternative Tax Policies: A Regional Disaggregated Model for Australia.” Economic Record 73, 305-314.

Feltenstein, A. and F. Plassmann. 2008. "The Welfare Analysis of a Free Trade Zone: Intermediate Goods and the Asian Tigers." The World Economy 31:7, 905-924.

Giesecke, J. A. 2011. "Development of a Large-scale Single US Region CGE Model using IMPLAN Data: A Los Angeles County Example with a Productivity Shock Application." Spatial Economic Analysis 6:3, 331-350.

Glaeser, E. and J.E. Kohlhase. 2004. "Cities, Regions and the Decline of Transport Costs." Papers in Regional Science 83, 197-228.

Haddad, E. and F. Perobelli. 2004. "Trade Liberalization and Regional Inequality - Do Transportation Costs Impose a Spatial Poverty Trap?" ERSA conference papers ersa05p700, European Regional Science Association.

Morgan, W., J. Mutti, and M. Partridge. 1989. "A Regional General Equilibrium Model of the United States: Tax Effects on Factor Movements and Regional Production." The Review of Economics and Statistics 71:626-635.

Morgan, W, J. Mutti, and D. Rickman. 1996. “Tax Exporting, Regional Economic Growth, and Welfare." Journal of Urban Economics 39:131-159. 
Partridge, M. and D. Rickman. 1998. "Regional Computable General Equilibrium Modeling: A Survey and Critical Appraisal.” International Regional Science Review 21:3, 205-248.

Radulescu, D. and M. Stimmelmayr. 2010. "The Impact of the 2008 German Corporate Tax Reform: A Dynamic CGE Analysis.” Economic Modelling 27:1, 454-467.

Rose, A., S. Liao. 2005. "Modeling Regional Economic Resilience to Disasters: A Computable General Equilibrium Analysis of Water Service Disruptions." Journal of Regional Science 45:1, 75-112. 